\title{
Crítica al control jerárquico de los regímenes políticos: complejidad y topología
}

\author{
NATHalie MeZZA-Garcia* \\ Carlos Eduardo Maldonado*
}

Artículo recibido: 21 de abril de 2014

Artículo aprobado: 21 de julio de 2014

Doi: dx.doi.org/10.12804/desafios27.01.2015.04

Para citar este artículo: Mezza-Garcia, N., \& Maldonado, C. E. (2015). Crítica al control jerárquico de los regímenes políticos: complejidad y topología. Desafíos 27(1), 121-158. doi: dx.doi.org/10.12804/desafios27.01.2015.04

\section{Resumen}

Los Sistemas Sociales Humanos (SSH) son sistemas complejos. Una de las mejores maneras de organizarlos es la auto-organización, la cual ha mostrado ser una óptima productora de orden en este tipo de sistemas, independientemente de si se trata de sistemas físicos, biológicos o sociales. Esta idea surge a partir de los desarrollos recientes en ciencias de la complejidad, los cuales ban enseñado que la vida es claramente el sistema más complejo que hay, emerge de mecanismos auto-organizados, es decir, no emplea ningún tipo de control central o externo para organizarse y, aun asi, es uno de los sistemas más ordenados que existen. Ello es razón suficiente para cuestionar el uso de mecanismos de control centralizados al intentar organizar sistemas tan complejos como los SSH. A partir de este cuestionamiento, este articulo presenta una crítica a las estructuras piramidales con jerarquias de control de los regimenes politicos desde las ciencias de la complejidad. El artículo sostiene que dado que los SSH son complejos, la mejor manera de organizarlos es la auto-organización, en lugar de tratar de imponerles orden desde arriba o desde afuera por medio de regímenes políticos con

\footnotetext{
* Investigadora independiente. Correo electrónico: mezzagarcia@gmail.com

** Profesor Titular, Facultad de Ciencia Política y Gobierno, Universidad del Rosario. Correo electrónico: carlos.maldonado@urosario.edu.co
} 
estructuras de control jerárquicas piramidales, verticales y descendentes. El articulo tiene un valor exploratorio o propositivo de cara a la teoría política.

Palabras clave: Sistemas Sociales Humanos, control, beterarquia, ciencias de la complejidad, auto-organización.

\title{
A Critique of Hierarchical Control of Political Regimes: Complexity and Topology
}

\begin{abstract}
Human Social Systems (HSS) are complex systems. One of the best ways to organize complex systems is by means of their self-organization, since the latter has proven to be an optimal producer of order in this type of systems, regardless of their nature: physical, biological or social. This concept emerged due to developments in the sciences of complexity, in which life has been understood as the most complex system that exists, and that does not require central or external control in order to produce organized patterns. Life's order stems from the self-organization of its internal and external dynamics and interactions. This fact serves to question the use of centralized control mechanisms when organizing human social systems, and underwrites a critique of pyramidal structures and control hierarchies in classical political regimes from the standpoint of the sciences of complexity. The paper argues that human social systems are complex systems; hence, the best way of organizing them is by letting them self-organize, instead of imposing - in a top-down manner, or from the outside - control by means of political regimes with hierarchical, pyramidal, or vertical structures. The paper explores this idea with a focus on political theory.
\end{abstract}

Keywords: Human Social Systems, control, heterarchy, the sciences of complexity.

\section{Crítica ao controle hierárquico dos regimes políticos: complexidade e topologia}

\begin{abstract}
Resumo
Os sistemas sociais humanos (SSH) são sistemas complexos. Uma das melhores maneiras de organizar os sistemas complexos é a auto-organização, a qual tem mostrado ser uma óptima produtora de ordem neste tipo de sistemas, independentemente de se trata-se de sistemas físicos, biológicos ou sociais. Esta ideia surge a partir dos
\end{abstract}


desenvolvimentos recentes em ciências da complexidade, os quais tem ensinado que a vida é claramente o sistema mais complexo que há, que emerge de mecanismos auto-organizados; é dizer, não emprega nenhum controle central ou externo para se organizar e, ainda assim, é dos sistemas mais ordenados que existem. Isto é motivo suficiente para questionar o uso de mecanismos de controle centralizados ao intentar organizar sistemas tão complexos como os SSH. A partir deste questionamento, este artigo apresenta uma crítica às estruturas piramidais com bierarquias de controle dos regimes politicos desde as ciências da complexidade. $O$ artigo sustenta que dado que os SSH são sistemas complexos, a melhor maneira de organizá-las é deixando que se auto-organizem, em lugar de tratar de impor-lhes ordem desde o topo ou desde fora através de regimes políticas com estruturas de controle hierárquicas piramidais, verticais e descendentes. $O$ artigo tem um valor exploratório ou propositivo de cara à teoria politica.

Palavras-chave: Sistemas Sociais Humanos, controle, heterarquia, ciências da complexidade, auto-organização.

\section{Introducción}

El rasgo principal de los sSH es su complejidad, es decir, son abiertos, descentralizados, emergentes y adaptativos, entre otras características. Esta clase de sistemas se conforma por tan diversas interacciones, que resultan altamente impredecibles ya que estas son sintetizadas de abajo arriba (bottom-up), por lo que no es posible anticipar lo que va a emerger de ellas. Asimismo, los SsH presentan dinámicas evolutivas y tienen una tendencia intrínseca a auto-organizarse - como también la tienen los demás sistemas complejos-. Más exactamente, los SSH son sistemas life-like ya que pueden ser descritos por medio de propiedades de los organismos biológicos (Sawyer, 2005). La biología y la ecología surgen, al mismo tiempo, como metáforas y marcos de comprensión para los sistemas complejos, en contraste con el modelo de la ciencia clásica que era la física.

A pesar de la tendencia hacia la auto-organización, históricamente han existido procesos de toma de decisiones consistentes en organizar los SSH por medio de regímenes políticos. Contrario al carácter mencionado de los SsH, los regímenes políticos se caracterizan por propie- 
dades que estructuralmente no reflejan ningún tipo de complejidad o uno muy bajo y que, incluso, se oponen a aquellas características y propiedades de los SSH. En otras palabras, los regímenes políticos son rígidos, inflexibles, no se adaptan, son cerrados y se espera que funcionen por medio de relaciones de causa-efecto. Ello quiere decir que los regímenes políticos funcionan como, y operan con, principios bastante cercanos a la física clásica newtoniana (Mainzer, 2007). En consecuencia, operan con control jerárquico impuesto de arriba abajo (top-down).

Este artículo sostiene que la auto-organización es la mejor manera en la que la organización política permite mayores y mejores grados de libertad. El objetivo del artículo es el de proponer el concepto de auto-organización sociopolítica como eje de la teoría política y como mejor alternativa al control jerárquico que los regímenes políticos vigentes emplean para organizar las comunidades humanas, para lo cual, sin embargo, se elabora la crítica del control jerárquico de los sistemas políticos.

La auto-organización se basa en bucles de retroalimentación positiva, que conducen a una complejidad creciente de los sistemas considerados y bucles de retroalimentación negativa, los cuales detienen o hacen retroceder interacciones que no sean convenientes para el sistema (Kauffman, 1995). Sus dinámicas y relaciones hacen que un sistema complejo evolucione y se adapte a las condiciones del entorno. La evolución implica transiciones de fase de los sistemas (Solé, 2011). Una transición de fase consiste en un cambio cualitativo de un fenómeno o bien en el cambio de la historia de un sistema.

Cinco argumentos sostienen al texto. En el primer argumento, se elabora una visión histórica de las topologías de los regímenes políticos, gracias a la cual se hace evidente la primacía de la topología de árbol. El segundo argumento pone de manifiesto la necesidad de entender los sistemas políticos como sistemas de procesamiento de información. El tercer argumento presenta el estado del arte de las relaciones entre teoría política y complejidad, tomando como punto central el estudio de la estructura organizacional. Se presenta igualmente la 
elucidación de la especificidad de la complejidad, notablemente de cara a la teoría política. El cuarto argumento elabora una crítica de las topologías de árbol, a partir de lo cual, en el quinto, sobre la base de las ideas de Kauffman (1995) y Camazine et al. (2001) se señala que la topología de árbol imperante en la organización política puede ser transformada y se muestra cómo admite otras topologías. Al final, se extraen algunas conclusiones.

\section{Visión histórica de las topologías de los regímenes políticos}

Un régimen político puede ser definido como el conjunto de reglas e instituciones que hacen prácticamente posible un sistema político. Los regímenes políticos se basan en la división de la sociedad política y la sociedad civil, entre gobernantes y gobernados. Esta división resulta problemática, puesto que crea una escisión entre la cima de la pirámide y la base. Aquella designa a los centros de poder, los tomadores de decisión, y a estos se les pide obediencia, seguimiento, "sentido de pertenencia". La estructura de los regímenes políticos en teoría de grafos y teoría clásica de redes corresponde a una topología de árbol, la cual expresa una estructura vertical, piramidal y rígida. La topología de los regímenes se impone sobre la estructura de red compleja de los SSH (figura 1).

El concepto de topología fue introducido en matemáticas gracias a la obra de S. Smale para designar transformaciones en el espacio que no admiten o tienen rupturas. La topología se divide en términos generales en estructural y algebraica, y constituye uno de los desarrollos más interesantes en ciencia, que ha sido escasamente atendido por parte de las ciencias sociales en general y la ciencia política en particular.

La topología de árbol ha sido la prevalente en la historia de los regímenes políticos, por lo menos en Occidente, y el hecho de que puedan haberse dado cambios en la manera en que se llega a los nodos ubicados en las partes superiores de esta clase de topología, o bien cómo se conservan en esos puestos, no ha producido históricamente 
ningún cambio estructural en el modo como se organizan los SSH. La figura 2 ilustra esta idea.

Figura 1. Regímenes políticos imponiendo orden por medio de control jerárquico sobre los Sistemas Sociales Humanos

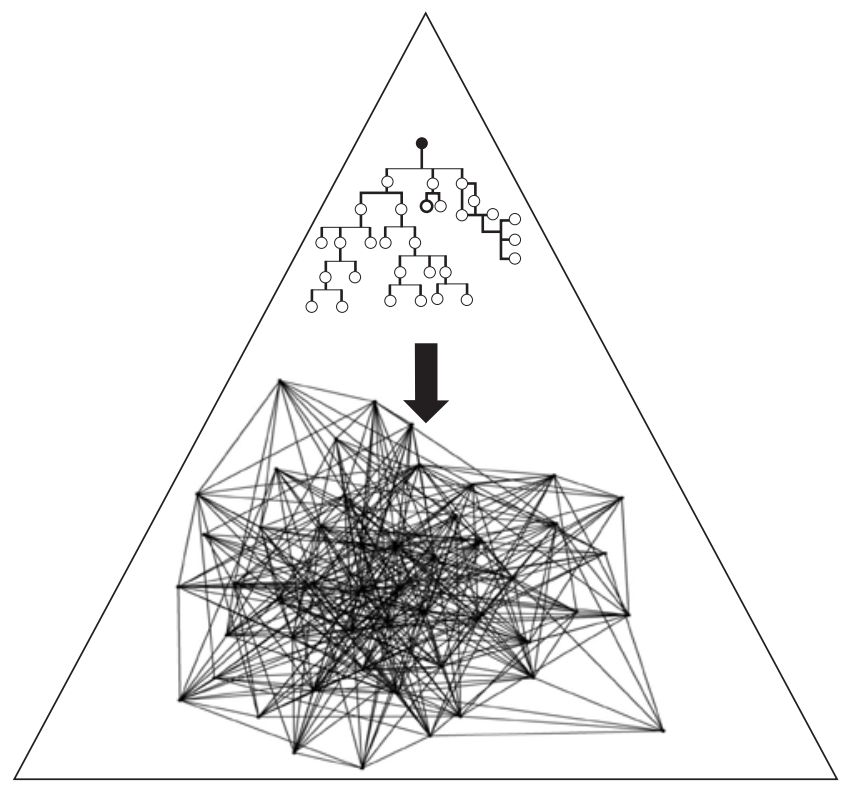

Fuente: Elaboración propia

La historia de Occidente empieza con la Polis griega en el siglo V a. e. v., luego de la Tiranía de los Treinta, con el tránsito del mito al logos y la llegada de los gobiernos de Solón y Pericles. Sin embargo, de acuerdo con Vernant (1992), el pensamiento griego puede rastrearse, sin dificultad, a partir del siglo VII e incluso VIII a. e. v. Las dos polis griegas más importantes, Esparta y Atenas, a pesar de luchar por sus distintos modos de organización política y social, eran bastante similares: ambas operaban con un control jerárquico expresado por medio de topologías de árbol que se imponían sobre el conjunto de los individuos de cada ciudad-estado y que no hacían parte directa del régimen. Esparta era una monarquía aristocrática. En los nodos superiores de su estructura se encontraban los espartanos (figura 2a) y estos se imponían sobre otros grupos humanos - como los siervos, que no tenían siquiera la posibilidad de intervenir en la 
vida política-. En contraste, Atenas (figura 2b) era una democracia. Tenía una asamblea de ciudadanos (la ecclesia) con un presidente en el nodo superior que se cambiaba a diario. Aunque existía una arena política en la que públicamente se tomaban decisiones concernientes a la ciudad, seguía existiendo un régimen que se imponía sobre el sistema social, pues solamente los hombres ciudadanos libres y con entrenamiento militar podían participar en los procesos de toma de decisión. Rossi y Rodríguez (2007) han estudiado el tema basándose en la obra de Aristóteles.

Por su parte, Roma fue una Monarquía, una República y un Imperio. Los tres periodos (figuras $2 \mathrm{c}, 2 \mathrm{~d}$ y $2 \mathrm{e}$ ) obedecen a modos de control jerárquico orientados a organizar a los lugares e individuos sobre los que se imponían. Con la caída del Imperio Romano se privatizó el poder político en manos de los señores feudales (condes, duques, príncipes), los cuales, a su vez, estaban subordinados a la autoridad del rey (el nodo superior), quien, en el caso europeo, tenía cercanas relaciones con la iglesia católica (figura 2f).

La Modernidad dio origen a los estados-nación en la forma en que los conocemos hoy día; democracias presidenciales contemporáneas (figura 2g), en los que la topología de árbol siguió conservándose. Posteriormente, en fecha más reciente, surgieron las dictaduras en algunas partes del mundo (figura 2i), las cuales son, abiertamente, estructuras jerárquicas, centralizadas, piramidales.

El estado social en la forma de democracias representativas surge después de la II Guerra Mundial. La gran mayoría con primer ministro, parlamentos, consejos o cámaras (figura 2j). Este modelo de organización política tiene la finalidad de garantizar derechos sociales a los individuos por medio de la creación de instituciones, aumentando así la importancia de los mecanismos de participación ciudadana, la influencia de los sindicatos y otros bucles de retroalimentación positiva o negativa provenientes de la sociedad civil. No obstante, el que incluso en ellas haya una separación entre los tomadores directos de decisión y el que estos se ubiquen en jerarquías de control en topologías de árbol hace que los regímenes contemporáneos 
compartan el rasgo principal de los regímenes políticos anteriores y, topológicamente no distan mucho de ellos. Ni siquiera en las democracias representativas contemporáneas, puesto que la sociedad civil es considerada a lo sumo como "el tercer sector".

En síntesis, el funcionamiento de un sistema depende en gran medida de su estructura y esta se ha mantenido por más de 2500 años. Así, la topología predominante en la historia de la civilización occidental es la de árbol con todas las consecuencias e implicaciones que ello acarrea: división, imposición, dominación, subordinación y exclusión, en una palabra: control.

La división entre la sociedad política y la sociedad civil ha impedido clásicamente procesos de auto-organización. De manera puntual, la auto-organización es un mecanismo efectivo para limitar las cascadas de errores en los regímenes políticos, gracias a que las interacciones entre los bucles de retroalimentación positivos y negativos ayudarían a auto-diagnosticar, auto-reparar, auto-corregir fallas de manera local, de la misma manera como estas propiedades lo hacen en otros tipos de sistemas (Vogel, 2000, Camazine et al., 2001). En el marco de las redes complejas, cascada de errores es el concepto que se emplea para designar una falla que se transmite en el sistema. Ello implica ausencia de flexibilidad o también exceso de robustez de un sistema, de suerte que se producen percolaciones, esto es, pequeñas alteraciones que acumulativamente terminan produciendo un cambio cualitativo en un sistema dado (Bak et al., 1988), con lo cual eventualmente el sistema termina siendo inviable.

En otras palabras, debe ser posible romper la barrera que existe entre la sociedad política y la civil. En efecto, la ausencia de un régimen con control jerárquico que impone sus decisiones sobre los SSH puede abrir la puerta a mayor auto-organización ciudadana, a mayores grados de libertad de un sistema social y político y consiguientemente a una mayor complejidad. Las interacciones sociopolíticas auto-organizadas serían una mutación en la evolución política, adaptada para hallar mejores y óptimas soluciones a problemas que nos atañen, así como para explorar mayores y mejores horizontes de acción y de vida. 
Hasta la fecha, en la descentralización política y administrativa puede verse cómo la complejidad aumenta en los regímenes políticos actuales. Sin embargo, dado que los procesos y mecanismos de descentralización partirían de las funciones de una estructura de árbol, es indispensable una mayor complejización topológica.

Se quiere sugerir que la geometría en general y la topología en particular emergen como marcos o instrumentos de estudio para la teoría política. Pues bien, un desarrollo particular de estas es la teoría de grafos, así como la ciencia de redes complejas (Barrat et al., 2009). La red compleja de los SSH permite estudiar cómo es posible que emerjan patrones globales sin ningún tipo de coordinación -local o global- y, por tanto, mayores posibilidades de hallar óptimos locales.

Figura 2. Topologías de Árbol en la Historia

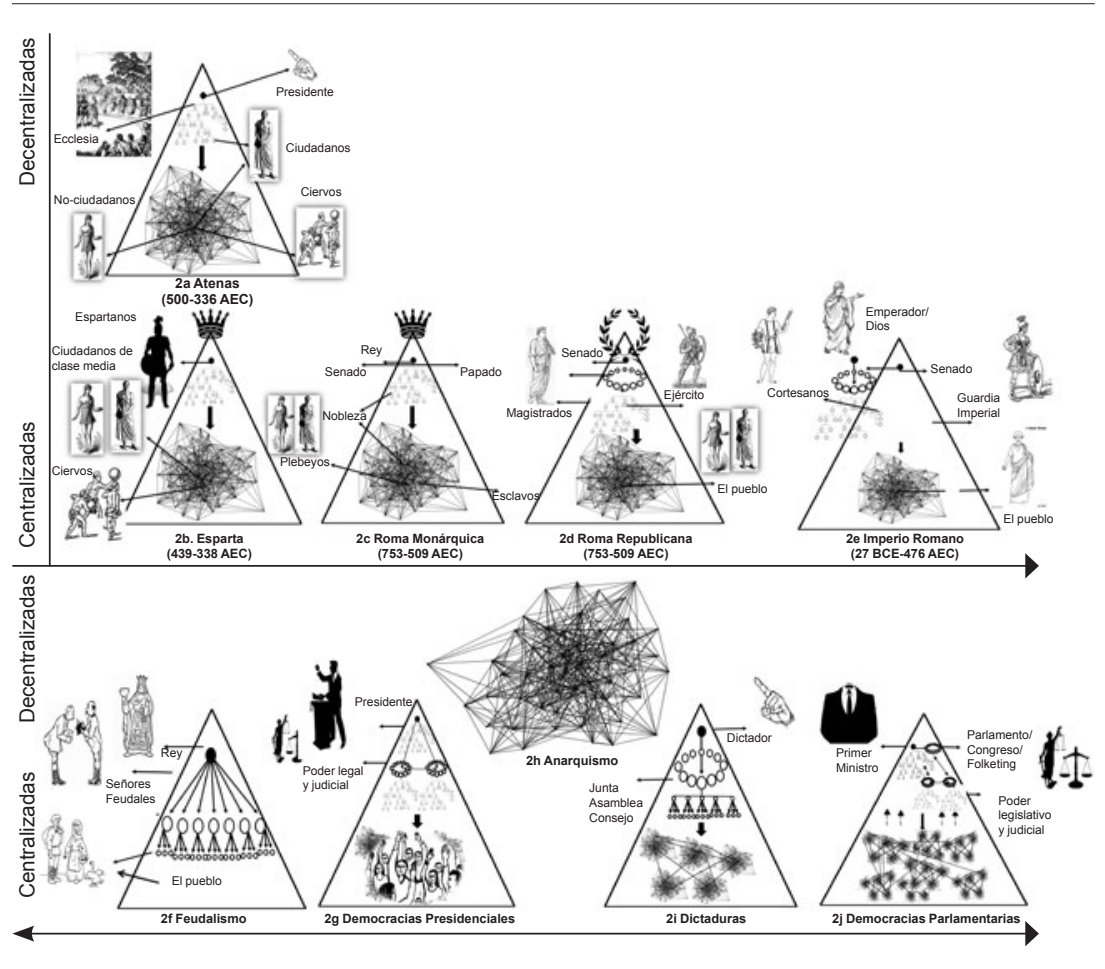

Fuente: Elaboración propia 
La auto-organización es un proceso interno de un sistema, y es el resultado de la evolución de este. Existe evidencia en la historia de que la estructura del poder político en el mundo conlleva a mecanismos violentos de acción colectiva, en la mayoría de los casos.

En fin, en una topología de árbol la cima de la pirámide toma decisiones sobre el resto de la estructura, que afectan a la estructura misma y al entorno, lo que impide un mejor aprendizaje, adaptación y ocasionalmente inclusión. Finalmente, sin ambages, cabe decir que las guerras y la violencia, en todas sus formas, son el resultado de esta estructura. La crítica y el rechazo de esta topología apuntan, en consecuencia, a una mayor flexibilidad, libertad, democracia y reducción o eliminación de la violencia política. En consecuencia, sería posible un mundo más tolerante y armónico.

\section{Los sistemas políticos como sistemas que procesan información}

De manera tradicional, se ha creído que en ausencia de una topología de árbol sería imposible manejar la complejidad y vastedad de los SSH. Por su lado, la autoorganización significa producir orden sin ningún tipo de control central o externo (Camazine et al., 2001).

El concepto de auto-organización en complejidad fue originalmente introducido por Nicholis y Prigogine (1977) y ha sido ampliamente reconocido como uno de los rasgos distintivos de un sistema o fenómeno complejo. En un nivel individual, los sistemas biológicos se auto-organizan, desde el desarrollo morfogenético y embrionario, hasta la célula, los tejidos (Kauffman, 1995), los órganos y sistemas del organismo. El organismo es un conjunto de patrones altamente auto-organizados. En consecuencia, bien entendido, un organismo vivo carece de control central y puede ser visto como un sistema de sistemas.

En un nivel poblacional, los sistemas sociales también se auto-organizan, desde las clases, familias, poblaciones, biomas, nichos ecológicos, hasta la biosfera. En complejidad, los estudios sobre inteligencia 
de enjambre (swarm intelligence): los bancos de peces, las bandadas de pájaros, las colonias de hormigas y las sociedades humanas, por ejemplo, han puesto suficiente relieve a la ausencia de un controlador central o externo en las estructuras y dinámicas poblacionales (Bonabeau, et al., 1999).

Algunos ejemplos de dinámicas de auto-organización pueden ser vistos en casos recientes como el movimiento de Indignados, la Primavera Árabe, Occupy Wall Street o el movimiento de estudiantes chilenos. Más exactamente, y de acuerdo con la inteligencia de enjambre, es posible hablar de liderazgo sin líderes y de estrategia sin estrategas. Los sucesos se desarrollan sin un controlador central, sin una visión global del sistema y sin un monitoreo individual sobre cada individuo. En efecto, la auto-organización es el mejor productor de orden en sistemas con numerosas interacciones no-lineales de elementos, con posibles configuraciones y en los que se producen siempre nuevos fenómenos y propiedades emergentes.

En rigor, el concepto de auto-organización es uno de los complementos al mecanismo de la selección natural en el estudio de la evolución de los fenómenos y son, por tanto, generadores de orden en sistemas complejos. La evolución y auto-organización del universo en los aproximadamente 13,7 billones de años así lo evidencian, el que el universo lleve aproximadamente este tiempo auto-organizándose demuestra que la interacción entre evolución y auto-organización es un gran productor de orden en sistemas de gran complejidad.

Ahora bien, la vida es el fenómeno más complejo que hay y aun así no necesita ningún tipo de control central para producir orden. Entonces, ¿por qué se intenta organizar a los SSH como sistemas novivos, por medio de control central, a expensas de su complejidad? ¿Pueden existir regímenes políticos que aprovechen las estructuras y dinámicas de los sistemas vivos incrementando, consiguientemente, su complejidad? Más exactamente, ¿pueden los regímenes políticos incorporar otras topologías, diferentes a las de árbol, aprovechar la complejidad y hacerse mejores fittest evolutivamente? 
Los sistemas políticos son modelos de toma de decisión, en los que se transforman ciertos inputs (demandas, recursos, apremios, etc.) en outputs (decisiones políticas) (Lapierre, 1976). Esto quiere decir que la principal función de un sistema político consiste en procesar información. Así, un enfoque computacional resulta conveniente en el estudio de las estructuras y dinámicas políticas. Computar significa procesar información y el procesamiento no es más que la conversión de una cosa - A, input- en otra - B, outputs- (Fraley, 2010). Biológicamente, computar equivale a la metabolización.

Adicionalmente, dado que el procesamiento en los sistemas políticos tiene la función de encontrar, no solo una decisión, sino la mejor decisión. Se define sistema político como un sistema computacional que busca resolver problemas de optimización en un marco sociopolítico (Mezza-Garcia, 2013).

Generalmente, el procesamiento de los sistemas políticos se ha entendido de manera lineal, secuencial, jerárquica y cerrada, siguiendo principios de causa-efecto y, a lo sumo, análisis de variables. Propiamente hablando, la referencia aquí a los sistemas políticos, a lo largo de la historia (polis, imperio romano, etc.) solo tiene la finalidad de mostrar la necesidad de un tipo de organización distinta a la compleja, en este sentido, se trata solo de ilustraciones que tienen en común la organización jerárquica y vertical (la intención de este artículo no es la de ahondar en los matices políticos en sentido histórico). En rigor, así entendidos y administrados, los sistemas políticos pierden la no-linealidad que tienen o pueden tener. Son parametrizados y algorítmicos.

Las figuras 3a y 3b ilustran modelos de sistemas políticos de dos de los teóricos más reconocidos en la temática, David Easton (1981) y Jean-William Lapierre (1976). Sus esquemas sirven para ilustrar el tipo de procesamiento lineal, cerrado y secuencial. 


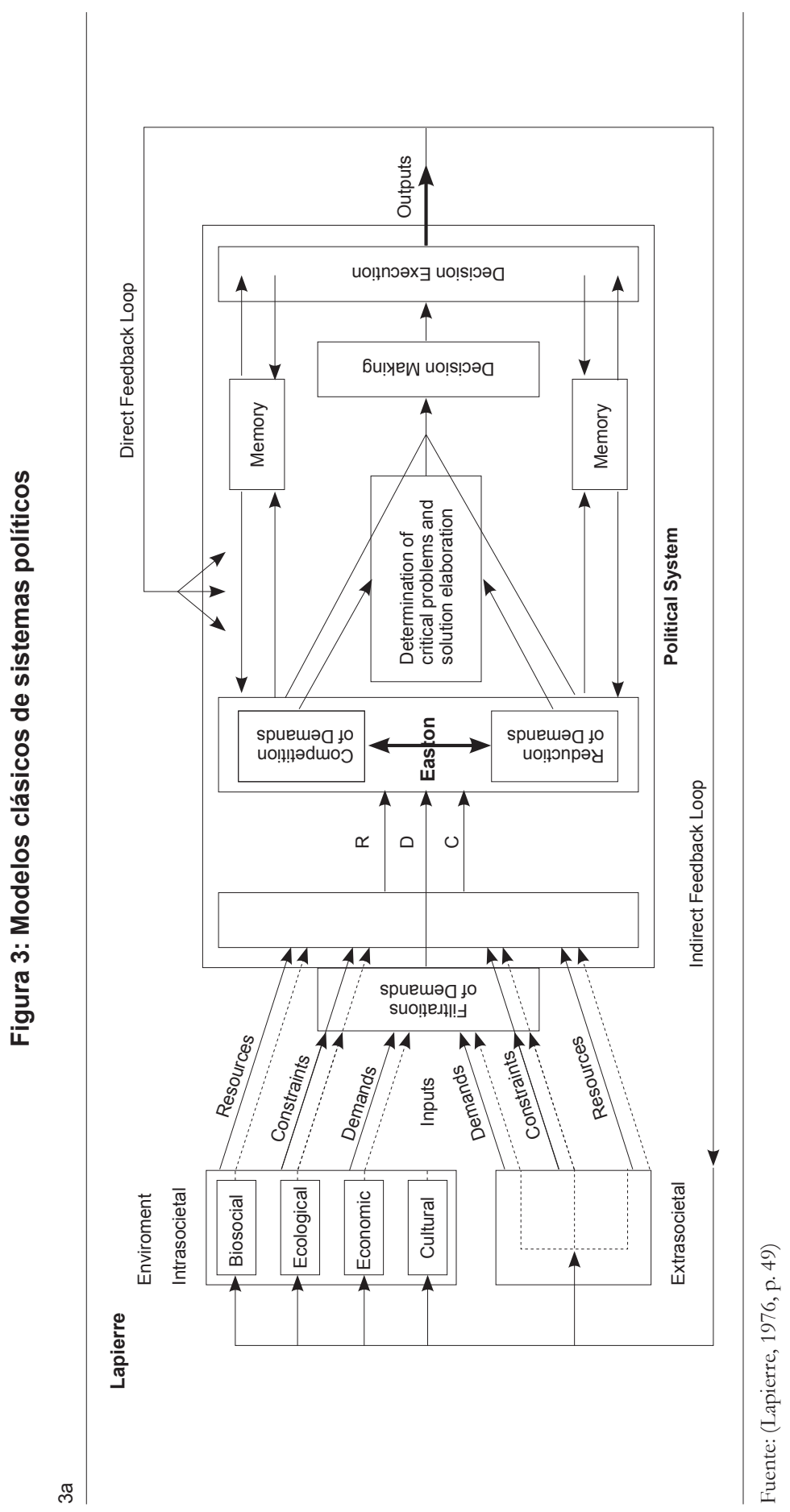




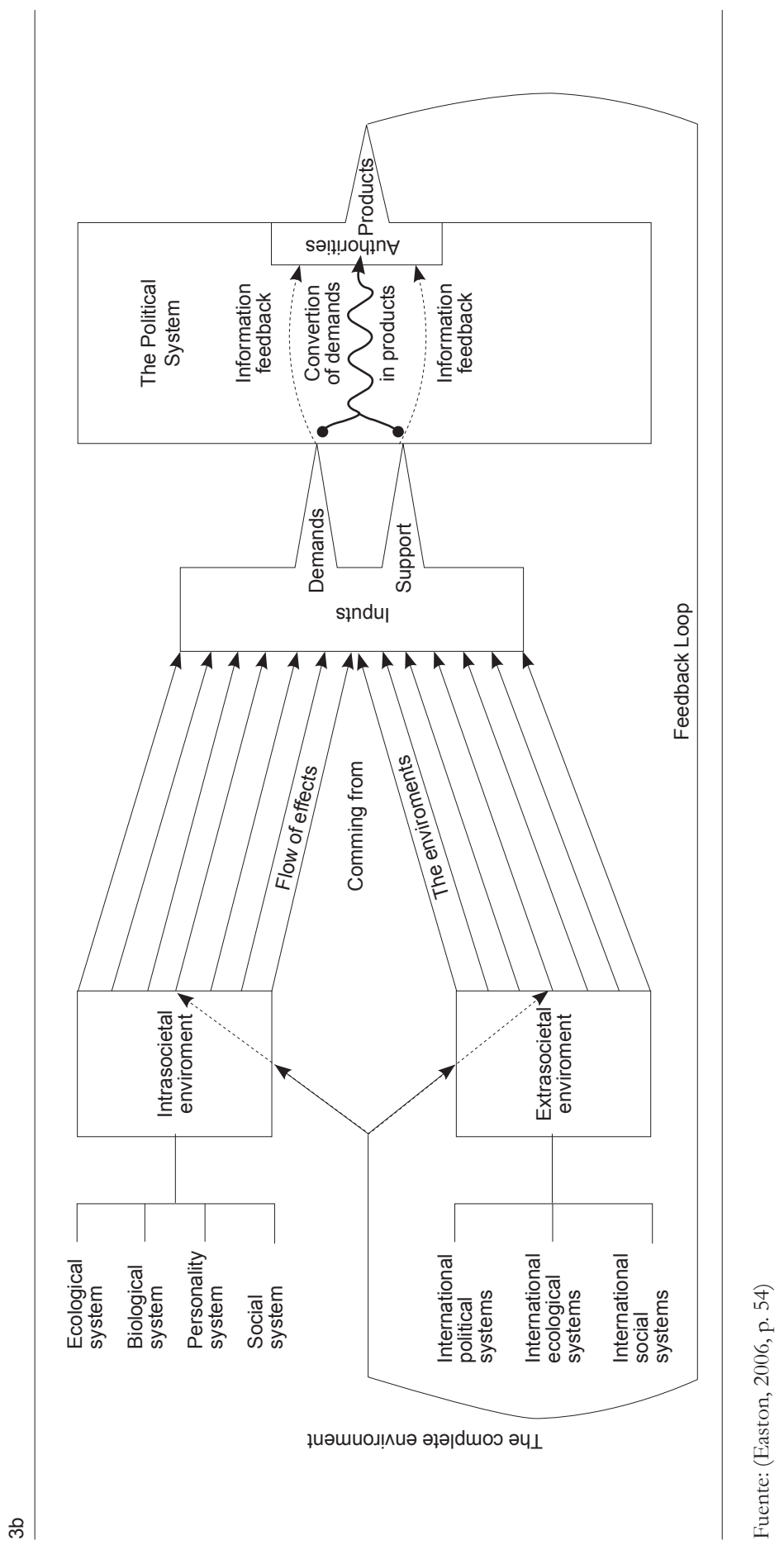




\section{Regímenes Políticos}

Los regímenes políticos son el aparato institucional de los sistemas políticos. En otras palabras, son los sistemas políticos llevados a la práctica. Los árboles tienen un nodo en la parte superior (que puede ser un rey, un primer ministro, un presidente, un emperador, etc.), y tienen un canal central. El procesamiento y mejor aún la distribución de la información sucede de arriba abajo y la iniciativa procede siempre desde arriba y por lo general se desatienden las demandas de los distintos agentes sociales. Justamente, en este sentido se habla de la cima del árbol como los tomadores de decisiones. La estructura de árbol implica una dinámica eminentemente rígida, poco flexible.

Si bien, las topologías de árbol se han mantenido durante siglos, ello no implica que sean la mejor estructura existente para conducir el ordenamiento de una sociedad. Por lo demás, son una estructura altamente frágil, pues basta con eliminar el nodo superior para que toda la estructura pueda colapsar aquí es fundamental atender a la distinción entre estado y gobierno. Como ha sido puesto de manifiesto en la literatura, se producen cascadas de errores. La figura 4 ilustra la topología de árbol (4a) y una cascada de errores (4b).

La teoría de grafos puede servir como base para la teoría sobre regímenes políticos, debido a que en ciencia política no existe una teoría sobre las propiedades topológicas - y, por supuesto, las implicacionesde las estructuras institucionales. En efecto, el funcionamiento de un sistema depende en gran medida de su estructura. O como sucede en biología: la estructura determina la función (Waddington, 2012).

\section{Complejidad, Sistemas Complejos y Ciencias de la complejidad}

La complejidad es un problema científico que surge debido a la existencia de sistemas o comportamientos no lineales. Son sistemas abiertos, marcados por gran incertidumbre, adaptabilidad, impredecibilidad, por tanto no deterministas, con la presencia de cambios súbitos y tendencia a auto-organizarse. Los regímenes políticos deberían tener estructuras que no impliquen aproximaciones reduccionistas. 
Figura 4: Topología de árbol y cascada de errores

4a. Topología de un árbol

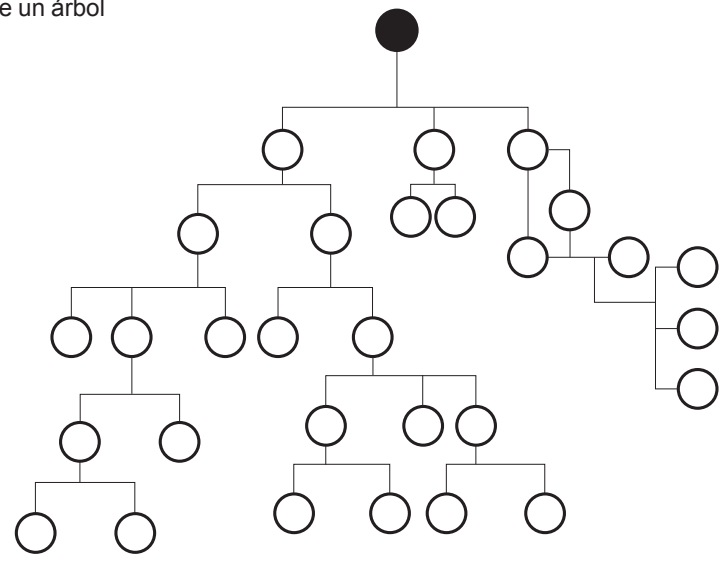

4b. Cascada de error

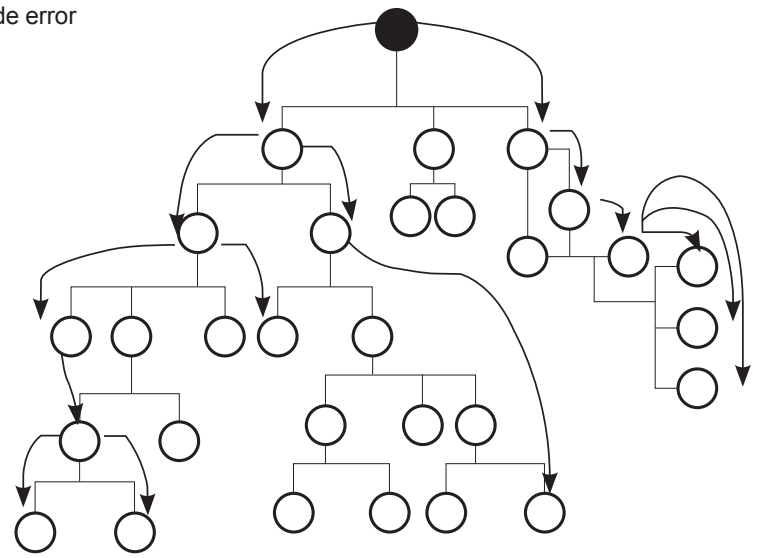

Fuente: Elaboración propia

Básicamente, existen tres tipos de problemas (Weaver, 1948): simples, complicados y complejos, que se ocupan de tres tipos de sistemas. Los sistemas simples son altamente predecibles y se explican como agregaciones de partes o bien inversamente por vía analítica, esto es división y separación de las partes. Por su parte, los sistemas complicados son conjuntos de sistemas simples y se explican en términos de promedios, estándares, vectores, estadísticas o matrices. En los sistemas complicados los inputs son proporcionales a los outputs y los grados de libertad de un sistema son muy bajos. 
Ahora bien, los sistemas complejos no se explican por vía agregativa o por análisis, ni tampoco se reducen a estadística (descriptiva o inferencial). Mejor aún, un sistema complejo no se explica por niveles anteriores o inferiores, sino por vía de síntesis. En la corriente principal de ciencia política los sistemas políticos han sido entendidos como sistemas simples o complicados. En otras palabras, en política se intenta dar explicaciones a problemas sociopolíticos partiendo de la sumatoria lineal de interacciones, recurriendo a comportamientos estándares (estadísticos) (Arrow, 1950). De esa manera, se ignora que uno de los rasgos principales de los sistemas complejos es la tendencia a producir comportamientos emergentes, lo que dificulta extremadamente su predecibilidad (Holland, 2000; Cansino, 2008).

Un sistema, fenómeno o comportamiento complejo son no lineales. Esto quiere decir que no existe una proporcionalidad o correlación directa entre los inputs y los outputs, ya que lo que emerge es más y/o diferente a la suma de sus partes o que el input (Holland, 1995). Un sistema complejo es esencialmente abierto, pues está en constante intercambio de información —o materia o energía - con su entorno. Por ello, un sistema complejo generalmente no presenta exactamente la misma configuración en dos momentos distintos. Los sistemas complejos son altamente impredecibles y sus estados futuros no dependen exclusivamente de estados anteriores o de determinadas condiciones iniciales.

Precisamente, debido a la no-linealidad, los sistemas complejos se auto-organizan. Esto es, producen patrones ordenados sin ningún tipo de imposición externa o superior y son capaces de adaptarse al entorno (Camazine et. al., 2001; Holland, 1995). En síntesis, un sistema, fenómeno o comportamiento complejo son abiertos, conformados por interacciones no lineales, evolutivos y altamente impredecibles. Estas características hacen que los sistemas complejos posean muchos más grados de libertad que un sistema simple o un sistema complicado. De hecho, un cambio pequeño en un tiempo inicial en un sistema de gran complejidad puede generar una serie de efectos inconmesurados o dinámicas caóticas a futuro (Lorenz, 1963). Este tipo de sistemas debería, tener un papel más central en el estudio de la política, pues 
la naturaleza de la gran mayoría de problemas de la ciencia política y de las relaciones internacionales es tener gran complejidad.

Las ciencias de la complejidad, por su parte, son un conjunto de ciencias que se han dedicado al estudio de los sistemas, fenómenos y comportamientos de complejidad creciente. Entre ellas, podemos mencionar la ciencia de redes, la teoría de catástrofes, la termodinámica del no-equilibrio y la teoría de fractales.

\section{Auto-organización}

La auto-organización consiste en la capacidad que tienen los sistemas complejos para producir patrones ordenados sin ningún tipo de control central o imposición externa (Nicolis \& Prigogine, 1977; Camazine, et al., 2001). Un ejemplo de un sistema físico auto-organizado en el universo son las galaxias en espiral (figura 5a), su forma es el resultado de leyes físicas del universo interactuando en el tiempo. A nivel biológico, los procesos de desarrollo embriológico (figura 5b) y los procesos de desarrollo morfogenético (figura $5 \mathrm{c}$ ) son también fenómenos auto-organizados. A nivel de poblaciones, los bancos de peces (figura 5c), las bandadas de pájaros (figura 5e), las colonias de hormigas (figura 5f) o las manadas de mamíferos (figura 5g) son fenómenos auto-organizados en donde la estructura global emerge como resultado de interacciones locales individuales.

A nivel sociopolítico, en situaciones y tiempos de crisis, las comunidades humanas se auto-organizan y nuevas formas y dinámicas emergen. En complejidad se dice que el sistema se acerca a o se encuentra en un estado crítico y puede producirse una bifurcación. La caída del muro de Berlín, La Primavera Árabe, así como los demás movimientos políticos auto-organizados de los años recientes (los levantamientos de estudiantes en Venezuela y los manifestantes en Crimea), son el resultado de interacciones locales entre individuos que llevaron a procesos de gran extensión. Lo evidente es que se trata de dinámicas imprevisibles, emergentes, que exhiben aprendizaje y adaptación, interacciones no lineales y total ausencia de correspondencia entre imputs y outputs, cuyas consecuencias desbordan el ámbito local. 


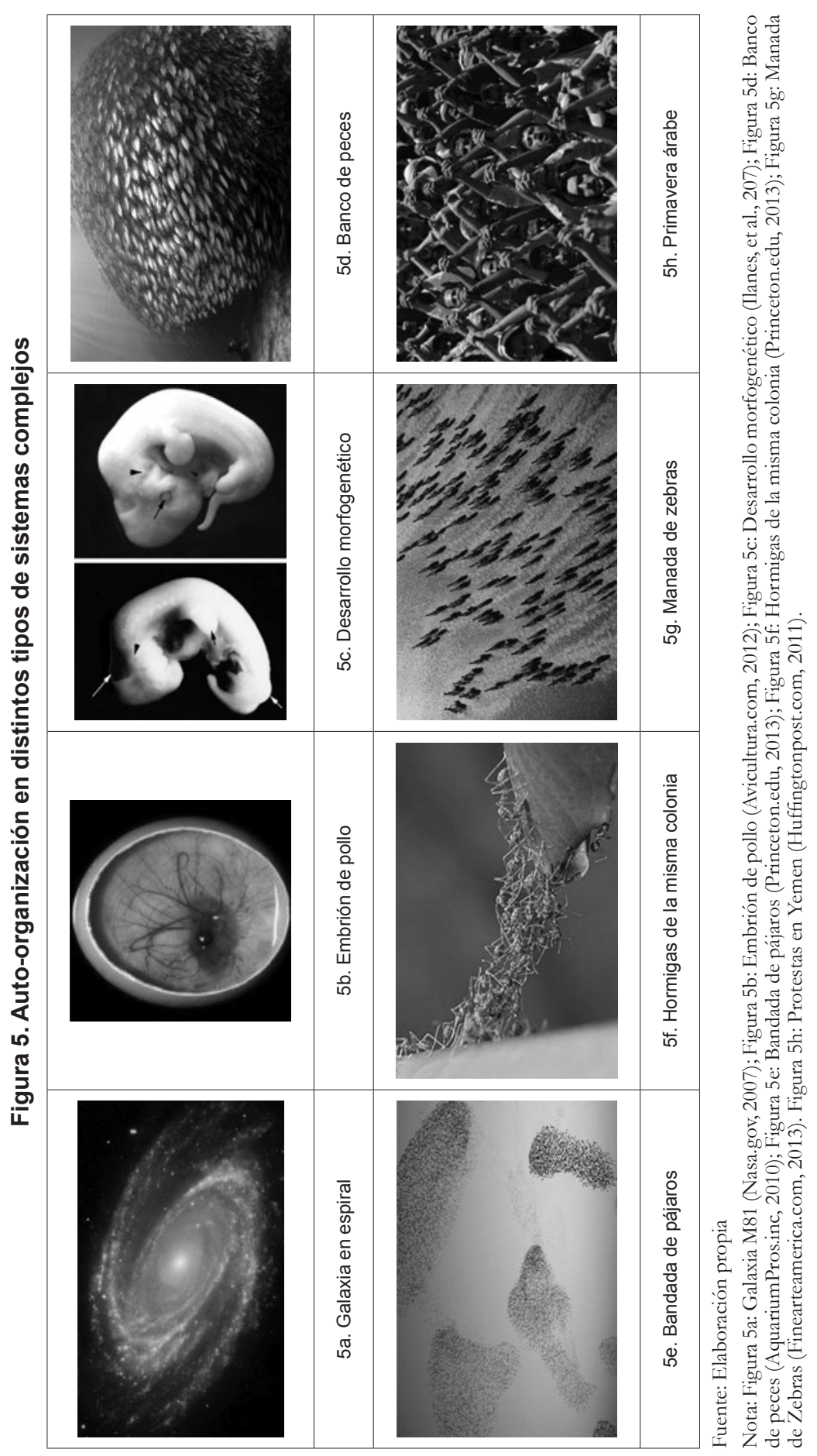




\section{Redes Complejas}

Las redes complejas (figura 6a) son la estructura más común que existe en el procesamiento de información en sistemas complejos. Estas redes son auto-organizadas y cada individuo (o célula, proteína, usuario de Internet, etc.), por medio de información directa que recolecta de su entorno, decide con qué, quién y cómo interactúar. Internet (figura 6b) es un ejemplo conspicuo de una red compleja. $\mathrm{Al}$ ser el resultado de una función de preferencia (preferential attachment) o del resultado de una decisión local, las redes complejas se caracterizan por tener unos nodos más atractivos que otros, logrando concentrar un mayor número de conexiones.

Figura 6. Estructuras de red compleja

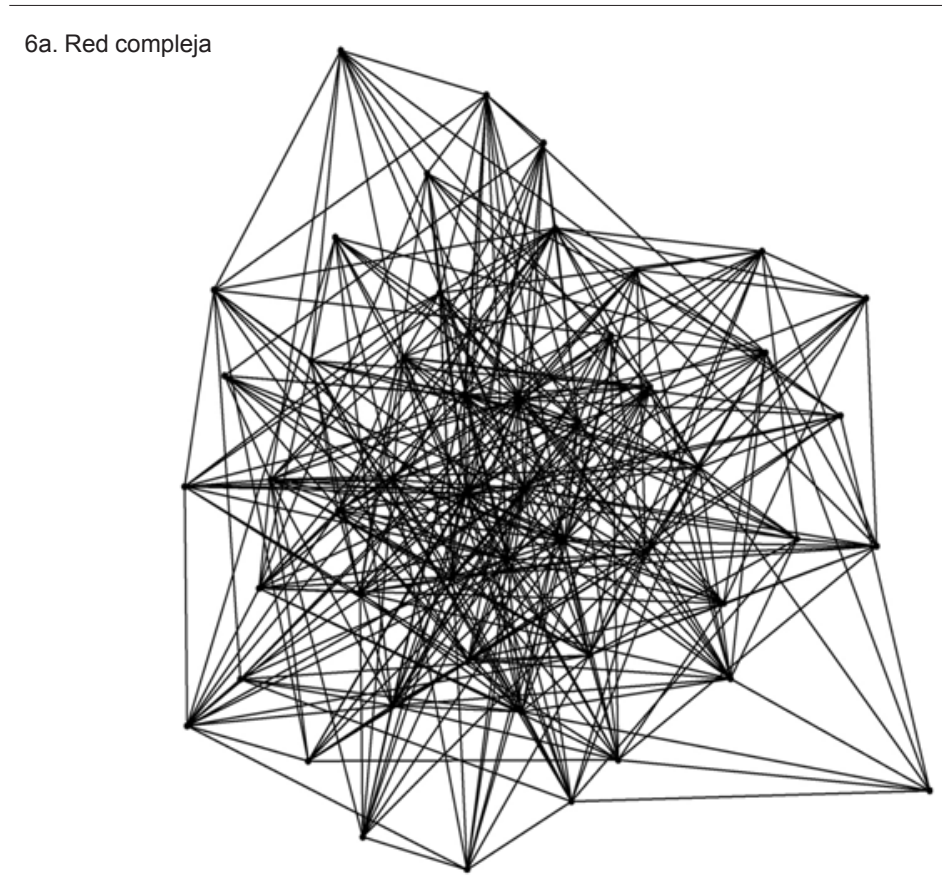

Fuente: Figura 6a: (Prettejohn, et al., 2011) 


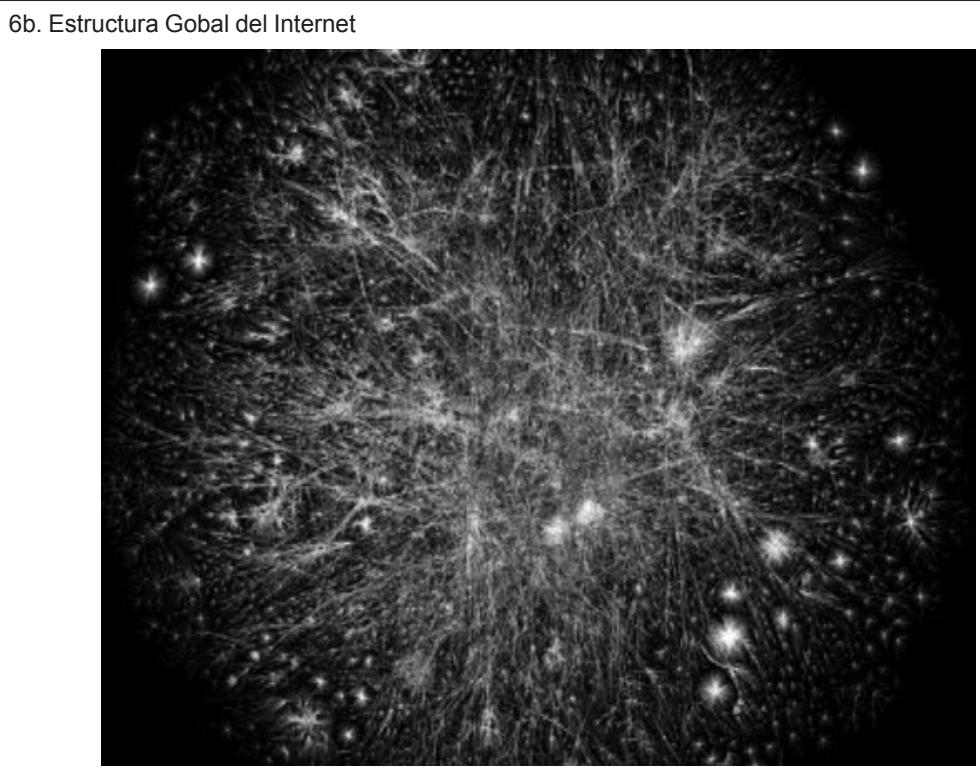

Fuente: Figura 6b: (Lyon, 2003)

En el caso de Internet, el preferential attachment como mecanismo principal de conformación de la red resulta en que existan algunos pocos motores, como Google, Yahoo, Twitter, Facebook, etc. que concentran un mayor número de conexiones que las demás como, por ejemplo, páginas web, si bien el número de estos es indudablemente mayor. Técnicamente, los nodos con el mayor número de conexiones se llaman hubs (Estrada, 2012). Estadísticamente las redes complejas son estructuras mucho más robustas que las topologías de árbol, ya que, al no haber un único nodo o un nodo principal encargado del procesamiento de información en la topología, es más difícil atacar a aquel nodo cuya eliminación haga colapsar la estructura. De igual manera, en caso de que un ataque en una estructura de red compleja vaya dirigido hacia un nodo específico, el sistema resulta menos frágil que en la topología de los regímenes políticos, puesto que el procesamiento de información depende de muchas interacciones y no de un único nodo o canal.

De manera tradicional, cuando se intenta organizar a los SSH se ha hecho en la forma de topología de árbol. Pero la verdad es que los ssH 
desbordan el máximo de procesamiento de información que puede alcanzar este tipo de topología (Mezza-Garcia, 2013).

\section{Breve estado del arte de estructuras organizacionales}

$\mathrm{Al}$ estudiar la estructura de las organizaciones se encuentra que son muy pocos los trabajos que han estudiado las implicaciones de la topología de árbol de los regímenes políticos para los sistemas sociales sobre los que se imponen (Bodin \& Norberg, 2005; Elgie, 1998). De hecho, los cambios de un tipo de gobierno a otro se asumen equivocadamente como cambios de un régimen político: presidencial, parlamentario (Colomer, 2001). Sin embargo, la verdad es que un cambio semejante no implica en manera alguna una transformación en la topología, como lo mostró la figura 2.

Cabe destacar tres conceptos en el estudio de las estructuras organizacionales de los regímenes políticos: jerarquías, heterarquías y anarquía. Estos tienen implicaciones e influencia sobre las propiedades estructurales así como sobre la función de organización de los SSH, tanto como sobre sus dinámicas.

Crumley (1995) divide las jerarquías entre jerarquías escalares —o anidadas- y jerarquías de control. Las primeras se refieren a niveles de organización en los que existe interacción a distintos niveles (partículas subatómicas, átomos, moléculas, células, tejidos, órganos, individuo, población, etc.). Allí, nivel no implica importancia. Así, una mutación a nivel celular puede generar cáncer en un individuo y llevarlo a la muerte e igualmente un trauma total en un organismo como consecuencia de un accidente puede hacer que todo su funcionamiento celular colapse en menos de un minuto. En otras palabras, resulta tan importante el cerebro como los demás órganos y sistemas para mantener la vida. Esto no es así en las jerarquías de control, pues en estas el nivel de organización superior determina órdenes de importancia o prioridad. Las jerarquías de los regímenes políticos son jerarquías de control en las que el comando de la estructura se rige de arriba abajo y el funcionamiento de esta se extiende más allá influenciando y dirigiendo en gran medida la organización de los SSH. 
De acuerdo con Fairtlough (2006), para pensadores tradicionales de la ciencia política como Webber o Hobbes, no pensar en términos de jerarquías resulta imposible porque se cree que su ausencia conduce a estados de anarquía - algo muy temido a lo largo de la historia e incrementalmente en el mundo contemporáneo-. Estos autores, centrales y tradicionales de la ciencia política, sin embargo, ignoran que hay estadios intermedios como las heterarquías que resultan mucho más ventajosos en contextos de gran complejidad como las sociedades humanas.

Una heterarquía es una estructura de red distribuida horizontalmente, en la que los procesos de toma de decisión están bastante descentralizados (Wilson \& Hölldobler, 1998). Es notablemente el equivalente en los enfoques contemporáneos del New Public Management a redes de redes que no se siguen por patrones top-down o jerarquías de control (O' Toole, 2004). Las heterarquías serían adecuadas para las estructuras organizacionales de los regímenes políticos futuros y contemporáneos ya que, como se dijo, los regímenes estructurados como topologías de árbol son poco eficientes ante dinámicas complejas de procesamiento de información.

Se hace evidente, entonces, por qué diversos autores del New Public Management o de la Administración - pero no propiamente de ciencia política- han reconocido que las organizaciones rígidas y jerárquicas dirigidas por medio de modelos de toma de decisión de arriba abajo resultan inefectivas (Meek, et al., 2007) o que las jerarquías de control contemporáneas, aunque estén descentralizadas —o se sigan de modelos de creación de política pública integral— no puedan manejar la complejidad del mundo contemporáneo (Bogason \& Musso, 2006). Esto se debe en parte a que las organizaciones se comportan como sistemas abiertos, dinámicos, adaptativos con interacciones no-lineales y no como sistemas cerrados y estáticos, por lo que resulta perjudicial imponerles estructuras de topología de árboles.

A pesar de que la mayoría de los regímenes políticos poseen topologías de árbol y jerarquías de control, la literatura demuestra que estas estructuras se dan por sentadas sin que exista un cuestionamiento 
o un estudio a fondo sobre las implicaciones de dicha topología. Adicionalmente, si bien la topología de árbol no logra representar el verdadero funcionamiento o el procesamiento de información en los regímenes políticos (figura 7), principalmente por las relaciones informales que se dan en su interior, generalmente se asume este tipo de topología como la adecuada o la mejor. Ello representa un problema sensible en la disciplina, puesto que si la principal función de los sistemas y regímenes políticos es organizar las sociedades hu-

Figura 7. Diferencia entre la estructura de una organización y su funcionamiento

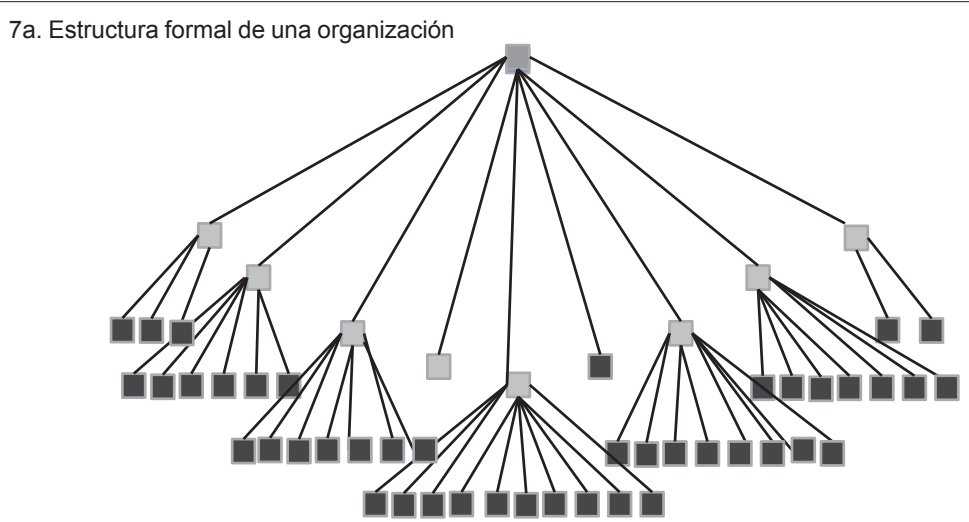

7b. Estructura actual de una organización

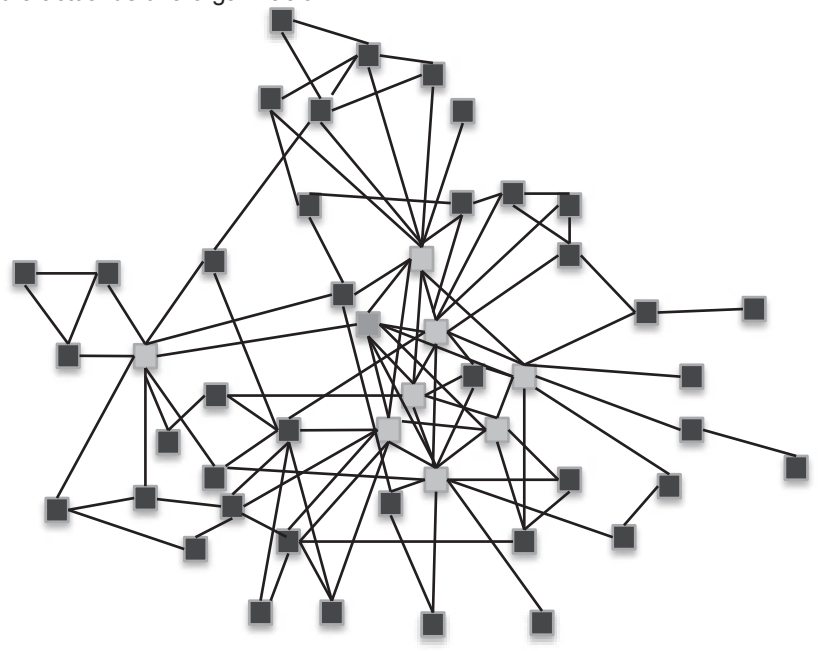

Fuente: Orgnet.com. Orgnet Consulting, Social Network Analysis Software and Services for Organizations, Communities, and their Consultants. 
manas - y sus entornos-, debería existir una teoría al respecto que se cuestione sobre los distintos modos de organización a partir de lo que estos son, contrario a suponer sistemas complejos. Por otra parte, en general, en la ciencia política, se le atribuyen comportamientos a los SSH en los que desconocen, ignoran o reducen sus atributos y propiedades derivadas de la no linealidad de sus interacciones.

Existen razones históricas para que en la corriente principal de los estudios políticos y la ciencia política se siga pensando en jerarquías de control. Algunas de ellas obedecen a la necesidad que crearon los primeros teóricos de la disciplina, como Thomas Hobbes (1928), John Locke (1988), Rousseau (2002) o Nicolás Maquiavelo (1910), ellos insistieron en la necesidad de tener sistemas y regímenes políticos imponiendo orden desde afuera o desde arriba sobre sistema social.

No considerar la complejidad de los SSH en ciencia política equivale a una aproximación reduccionista sobre el comportamiento de los individuos, los entes locales, las naciones, los grupos humanos, los sistemas sociales y sus interacciones. En este sentido, hacen falta avances en la teoría sobre regímenes políticos que conduzcan a una mejor práctica. Es decir, desde la teoría de los regímenes políticos se les debería dotar de dinámicas y topologías que puedan operar de manera adecuada en entornos complejos y puedan, incluso, aprovechar la complejidad. Este trabajo apunta hacia la necesidad de trabajar en esa dirección. Para ello, es preciso pensar otro tipo de estructuras que se alejen del funcionamiento de las topologías de árbol y, en donde las jerarquías, de haberlas, sean anidadas y no de control. Un argumento en contra de las jerarquías de control es que en ellas se asume que el control sobre los sistemas sociales y los estados-nación deban contener la totalidad y diversidad de la población y unificarla bajo una serie de símbolos y factores formales integradores.

Un argumento a favor de las heterarquías es que, dada la complejidad de los sistemas sociales humanos, un control jerárquico no implica la producción del efecto esperado, como si se tratara de sistemas simples, cerrados, lineales o complicados. La figura 8 muestra distintos tipos de topologías, la 8a es una topología de árbol, la 8b ilustra una red de 
bus, la cual tiene también solo un canal central para el procesamiento de información. La topología de estrella (figura 8c) tiene un nodo en el centro del cual todos los demás dependen. La estructura de la $8 \mathrm{~d}$ es una topología de anillo, en la que cada nodo tiene contacto con sus vecinos y ninguno se considera de mayor importancia que los demás. La 8e muestra una topología en la que cada uno de los nodos se conecta con los demás, la 8f representa una topología de malla. Las siguientes dos imágenes (figura 8g) son ejemplos de topologías con estructuras fractales, es decir, formas que repiten su escala global en menor tamaño y la topología (figura $8 \mathrm{~h}$ ) es un ejemplo de redes aleatorias. Por último, la $8 \mathrm{i}$ muestra un ejemplo de una estructura de red compleja.

Por otra parte, la figura 9 ilustra cómo la teoría de grafos puede ayudar a pensar topologías que sepan operar mejor en contextos de gran complejidad. En el eje $x$ se ubican las estructuras, desde las más centralizadas a las más descentralizadas, en el eje y se ubican las estructuras dependido de su complejidad. En el punto 0.0 localizamos las de

Figura 8. Topologías clásicas, híbridas y complejas

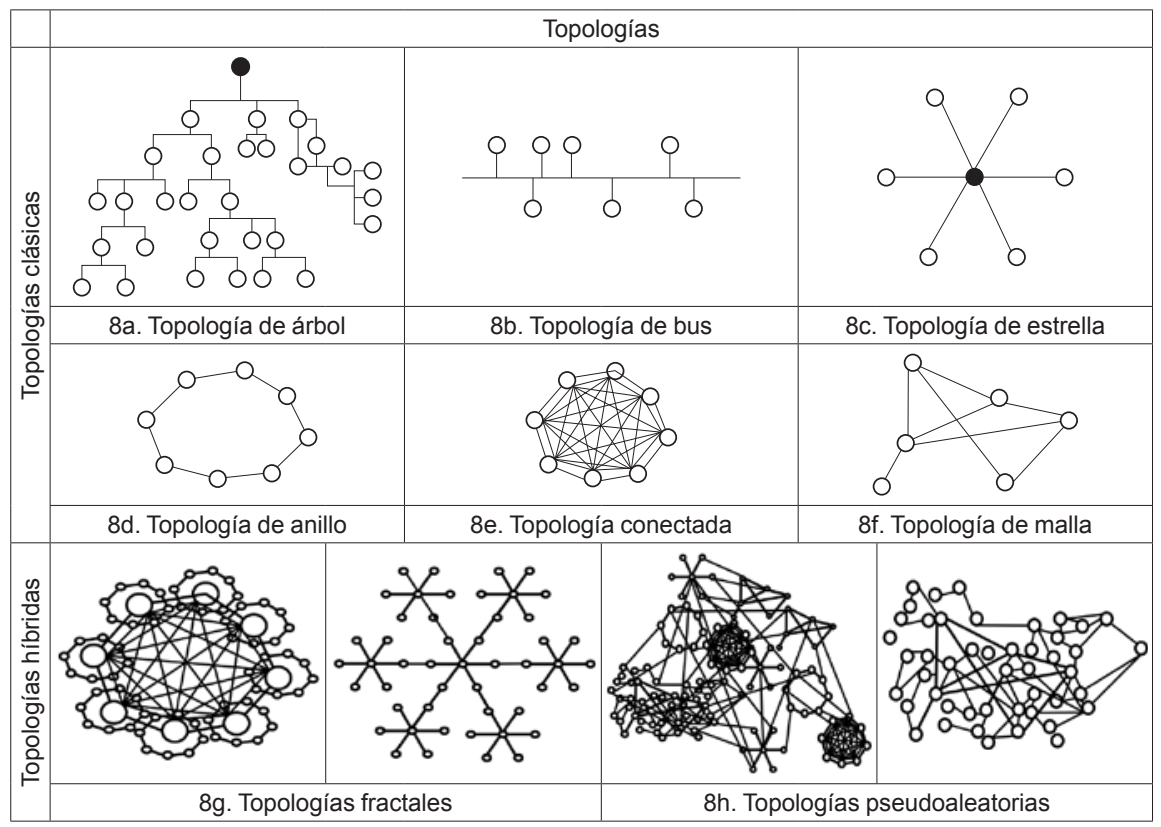




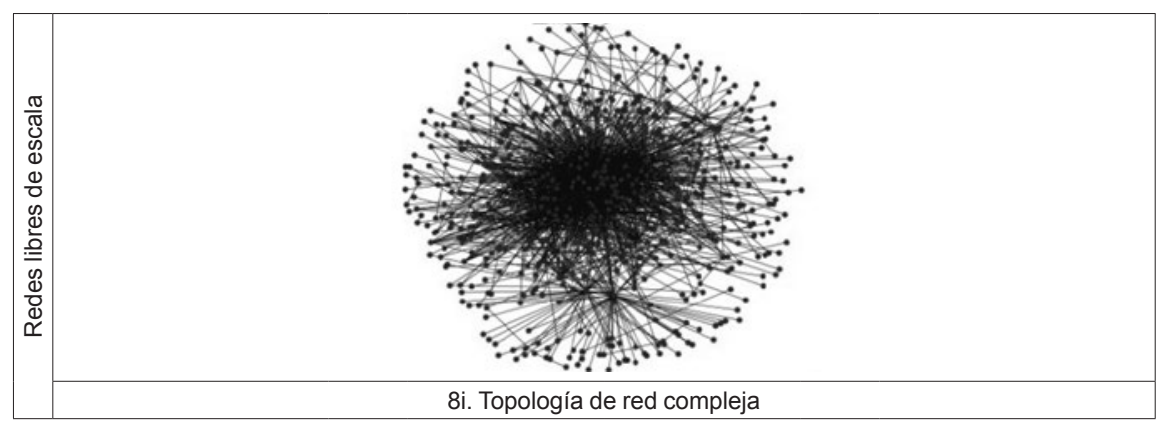

Fuente: (Mezza-Garcia, 2013).

Figura 9: Topologías según su descentralización, complejidad y cercanía con modelos bio-inspirados

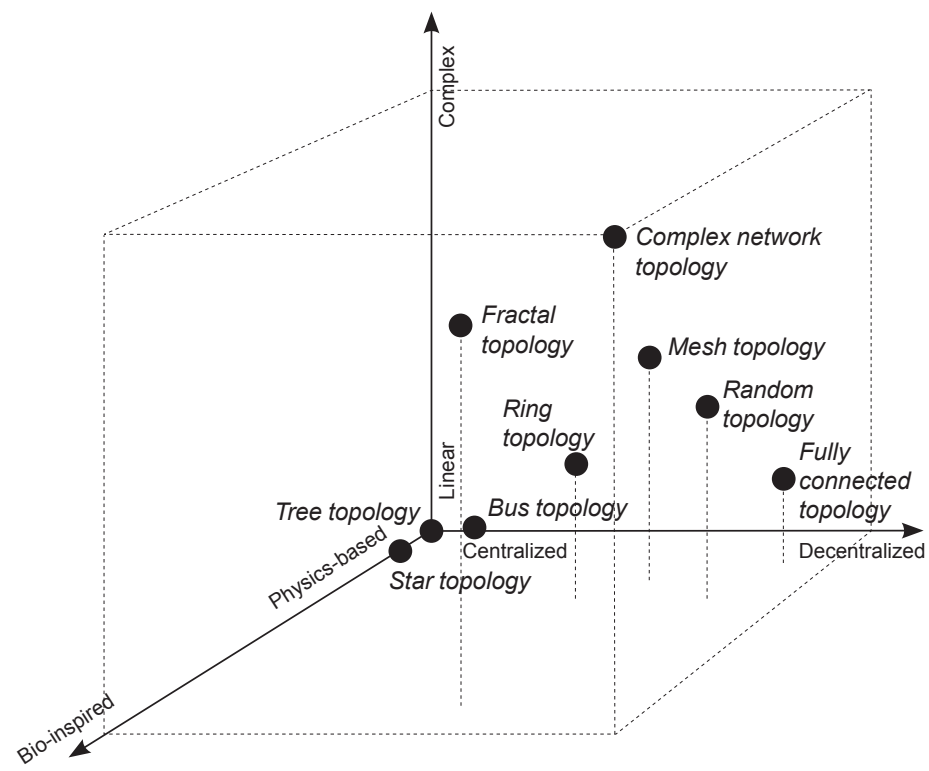

Fuente: (Mezza-Garcia, 2013).

menor complejidad y hacia arriba aquellas con mayor complejidad. Por último, en el eje zlas topologías se ubican según su cercanía con la física (en el punto 0.0) y a medida que se alejan del centro según su cercanía con modelos topológicos más bio-inspirados.

En síntesis, la creación de teoría sobre los regímenes empleados para su organización no debería descartar ni ignorar la no linealidad de las 
dinámicas sociopolíticas. De hecho, la naturaleza compleja de los SSH debería ser el punto de partida de la teoría sobre regímenes políticos. Este planteamiento se extiende desde pequeños grupos sociopolíticos hasta lo que hoy se conoce como sistema internacional, en el que las naciones interactúan con otras de manera no lineal en espacios abiertos, lo que da como resultado un sistema global complejo adaptativo (Maldonado, 2014).

\section{Crítica de las topologías de árbol y grados de libertad}

Cabe destacar dos libros que contienen los estudios de los atributos generales de la auto-organización, At Home in the Universe (Kauffman, 1995) y Self-organization in Biological Systems (Camazine, et al., 2001). El propósito en esta sección es extrapolar estos enfoques en la auto-organización de los SSH. Así, se introduce el concepto de auto-organización sociopolítica, definida como las dinámicas políticas en los SSH que emergen de manera autónoma en interacciones que se desarrollan usando solo información local y que no obedecen a ningún principio o gobierno en particular.

La auto-organización es posible en sistemas con un número de elementos que comparten características en común (Camazine, et al., 2001), tales como ser parte de una misma especie o de una misma comunidad. Camazine et al. explican que el orden a partir de la autoorganización es una emergencia natural de todo sistema complejo. Su argumento principal es que, dada la complejidad y el número elevado de elementos e interacciones que se dan en sistemas de gran complejidad, es imposible que haya uno solo - o unos cuantos individuoscapaces de supervisar y monitorear la posición y actividad de cada uno de los demás pertenecientes al sistema con el fin de guiar la actividad de todos hacia una meta específica, "en términos de procesamiento de información, tener un sistema complejo liderado o regido por una autoridad central requiere una red efectiva de comunicación y habilidades cognitivas sofisticadas - si no imposibles- por parte del planeador central"' (Camazine, et al., 2001, p. 8). 
Consiguientemente, se propone, entonces, que la auto-organización socio-política es una alternativa más viable para organizar los SSH que el control jerárquico, ya que es extremadamente difícil que un líder que pueda saber todo lo que está sucediendo en un sistema en cada momento y tomar la mejor decisión (Wachhaus, 2012). Esto es, lo que afecta a un sistema en un tiempo $a$ de determinada manera, lo afecta de una totalmente distinta en un tiempo $b$ (Maldonado \& Gómez Cruz, 2011). En efecto, ningún proceso deliberativo puede cambiar el hecho de que las posibles soluciones a problemas que se dan en entornos complejos sean tan elevadas que no exista ningún sistema humano en la tierra capaz de evaluarlas todas para posteriormente tomar la mejor decisión.

Incluso, con los computadores más avanzados que existen hoy día, hallar la mejor solución a un problema de complejidad creciente tomaría más tiempo que toda la historia del universo. Esto se conoce en complejidad como los problemas de optimización, los métodos empleados son las metaheurísticas. Estas permiten, en un contexto sociopolítico, explorar mejor el espacio de soluciones de un problema. Aun así, las metaheurísticas eligen una solución por motivos prácticos porque, de igual modo, para problemas no lineales con un elevado número de elementos la exploración de las soluciones podría tomar un tiempo infinito. En rigor, los sistemas complejos son probabilísticos.

Matemáticamente, a este escenario de los posibles estados de un sistema se le conoce como espacios de configuración" (Kauffman, 1995). Este incluye todos los posibles comportamientos que un sistema puede adoptar. En el caso de los SSH, su complejidad es tal que su espacio de estados es inmenso. El espacio de configuración está dado por la ecuación $N^{K}$, en donde $N$ representa el número de nodos de la red y $K$ el número de interacciones posibles entre los nodos. Por ejemplo, para un grupo humano conformado por tan solo cincuenta individuos, cada uno puede interactuar exclusivamente con otros dos en interacciones aisladas, el número de espacios de estado está definido por $2^{50}$, lo cual da un resultado de 1.125.899.906.842.624 posibles configuraciones. 
Ahora, es evidente que las sociedades humanas tienen una cifra no de cincuenta, sino de varios millones de individuos interactuando con cientos o miles de distintas maneras en distintos niveles, de distinta naturaleza (figura 11). Surge así el cuestionamiento de qué tan favorable es tener topologías centralizadas con jerarquías de control tomando decisiones ante tal complejidad.

Figura 11. Interacciones en distintos niveles

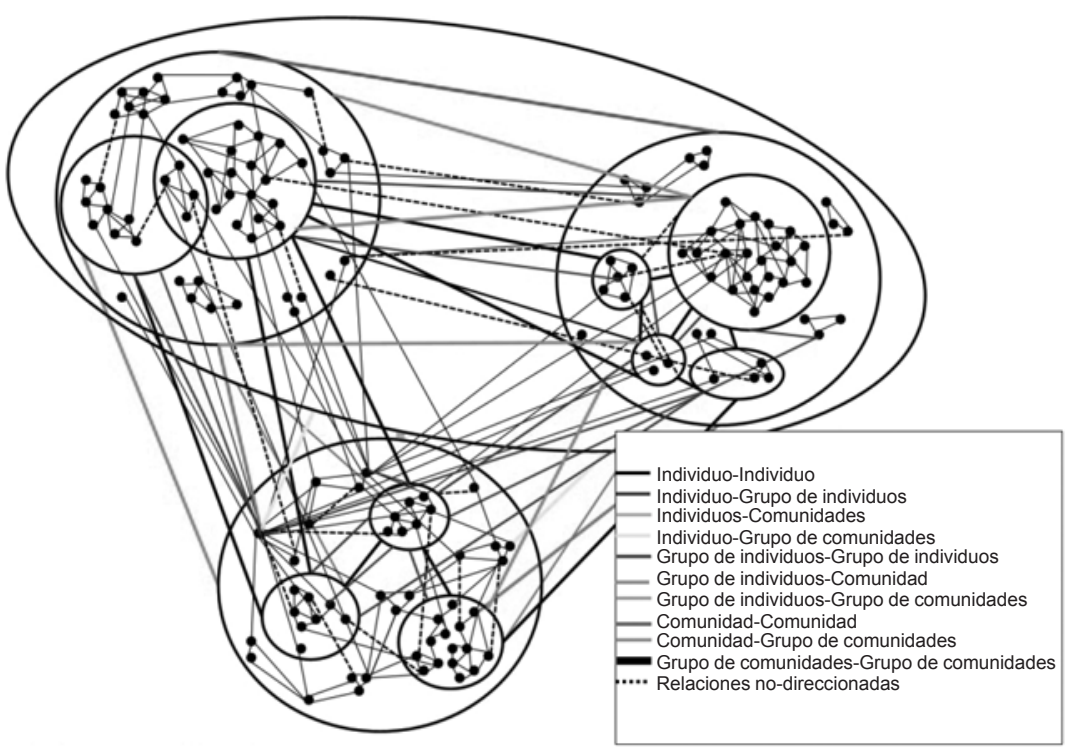

Fuente: Elaboración propia

Lo mejor que se puede hacer en estos casos es tratar de hallar óptimos locales. Para ello, se necesitan mecanismos descentralizados y emergentes de toma de decisión y, por supuesto, regímenes políticos, instituciones, organizaciones, etc. con topologías cuyo funcionamiento se acerque al tipo de entornos y tiempos caracterizados por complejidad creciente.

\section{Introduciendo topologías de mayor complejidad sin ningún control central}

Un régimen político que opere hallando óptimos locales y que, efectivamente, logre producir patrones organizados en un sistema social 
humano debe ser capaz de guiar la propia auto-organización del sistema social y no imponer algún tipo de orden preestablecido sobre este, dada su complejidad. Existen, en efecto, demasiadas dinámicas de incertidumbre y demasiadas interacciones que considerar que se trata de un sistema predecible. La imposición, en estos casos, no resulta adecuada. La auto-organización sociopolítica es una solución viable a este problema, pues en ella cada individuo o grupo decide con quién o cómo interactuar, siguiendo decisiones locales de preferencia, por lo que la estructura y dinámicas resultantes son una síntesis de interacciones locales y no una imposición externa al sistema. ${ }^{1}$ De esa manera, no hay un colegiado de individuos que se impongan sobre otro grupo con menores ventajas en la organización de los sistemas sociales a los cuales pertenecen.

Si en un ámbito sociopolítico a los grupos y comunidades humanas se les permite organizarse e interactuar, sin necesidad de legitimar sus dinámicas por medio de un único canal central en una topología de árbol, es probable que las topologías sufran transformaciones como las presentadas en la figura 12.

Lo anterior puede llevar a que emerjan más meso niveles y estructuras híbridas heterárquicas como consecuencia de interacciones no lineales en las maneras en las que los individuos se comunican; en otras palabras, estructuras menos frágiles que las topologías de árbol y, por tanto, de mayor complejidad. Lo anterior hasta llegar a la estructura de redes complejas.

Una razón por la cual es posible que las redes complejas sean la estructura resultante de la complejización topológica de los regímenes políticos se debe a que la estructura básica de estas tiene tres nodos conectados (triángulos), una característica también presente en las relaciones informales de los sistemas sociales humanos, pues, generalmente, los individuos son amigos de los amigos de sus amigos

\footnotetext{
1 Desde un punto de vista de complejidad, local no implica, necesariamente, proximidad geográfica; un individuo puede interactuar con otro en un lugar antípoda del globo y aun así dicha interacción se considera local.
} 
Figura 12. Variación de la topología de árbol en otras topologías

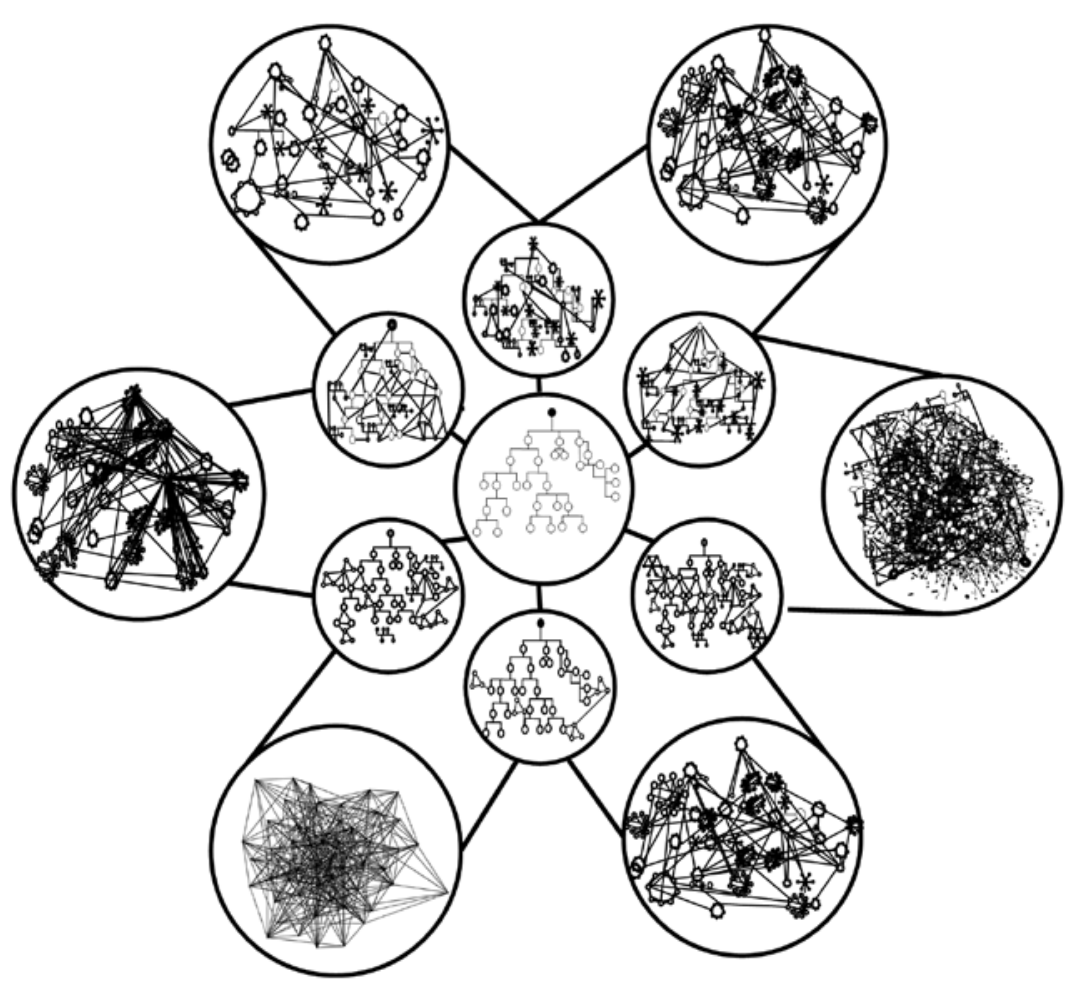

Fuente: Elaboración propia

(Watts, 2003). Por ende, si en los regímenes políticos se flexibilizan las conexiones, posiblemente lo que se guíe la estructuración del sistema sería la estructura de las relaciones informales.

Igualmente, es altamente probable que las funciones de los distintos nodos-régimen se aniden en jerarquías escalares, generando topologías emergentes que presenten autosemejanza o fractalidad. Especialmente si las anteriores son el resultado de procesos de optimización más aleatoriedad, dos factores que influyen en la emergencia de una red compleja. Mejor aún, dado que las redes complejas emergerían de la complejización de las topologías de árbol en los regímenes políticos, ello significaría un mejor procesamiento de información en ambientes de gran complejidad. Puede decirse que un mejor procesamiento de información implicaría mejores sistemas políticos y modelos de toma 
de decisión. En consecuencia, es muy probable que esto lleve a una mejor organización de los $\mathrm{SSH}$, a una mejor exploración de los espacios de fase y el espacio de soluciones y, posiblemente, a patrones espontáneos más organizados, diversos, incluyentes e incluso armónicos.

Topologías de redes complejas como el patrón emergente de la autoorganización sociopolítica desembocarían en la emergencia de regímenes locales abiertos: SSH auto-organizándose, auto-controlándose, auto-configurándose y re-configurándose. No obstante, de cierta forma puede descartarse que en algunas subredes emerjan jerarquías de control. Con la diferencia de que ya no serían una imposición de la tradición sobre los SSH. Por el contrario, estas jerarquías de control emergentes, anidadas en la red compleja anárquica o heterárquica, obedecerían a dinámicas y necesidades propias del sistema y no a factores de poder despótico o tradición y en todo caso serían siempre provisionales.

Esta propuesta permite avizorar una tendencia: cada vez más los sistemas políticos incluyen mayor diversidad de manera formal, incluso sin prever las consecuencias en el largo plazo que ello pueda tener para los regímenes y sistemas políticos tal como los conocemos hoy.

El flujo rápido de información en Internet y la tendencia hacia un mundo globalizado seguramente amplificarán los alcances de nuestra propuesta, pues este ya ha sido punto de partida para algunas dinámicas sociopolíticas auto-organizadas en el mundo contemporáneo, como las mencionadas en secciones anteriores.

Uno de los principales problemas que han tenido los fenómenos sociopolíticos auto-organizados de los años recientes es que la autoorganización ha sido manipulada para intentar llegar a una topología de árbol o para tumbar el nodo superior, tal y como sucedió en algunos países de la llamada Primavera Árabe, como en Siria y Egipto. Es decir, conservar la estructura, pero cambiando los individuos en los nodos de superiores, lo cual equivale a recaer en los mismos tipos de modelos de organización anteriores a las dinámicas de autooganización. 
Contrario a lo que ha sucedido en los últimos 2500 años, los SSH requieren transformaciones profundas para que las colectividades humanas adquieran mayores grados de libertad. Para ello, es necesario que las reglas de actuación e inclusión política co-evolucionen entre la creatividad y la innovación en espacios de armonías fluidos.

\section{Conclusiones}

Hemos presentado por qué las estructuras piramidales con control jerárquico en los regímenes políticos no son una manera adecuada de organizar la complejidad y vastedad de los SSH. Las ciencias de la complejidad nos permiten presentar una crítica y una propuesta innovadora.

Hemos querido mostrar que los cambios en la forma en la que se llega al poder no equivalen a transformaciones en el funcionamiento de los regímenes políticos, a menos que se dé también una transformación topológica. Apuntamos, así, a la necesidad de pensar otros tipos de topologías, dado que vivimos en contextos y tiempos de complejidad creciente. Cabe apuntar hacia otros tipos de sistemas para que las organizaciones políticas vayan más acorde con la naturaleza compleja de los SSH. Así, podremos tener interacciones políticas con gran armonía.

De manera interesante, topológicamente el modelo de toma de decisión con organizaciones políticas que más se acerca a la estructura de los ssH complejos son los sistemas anárquicos (figura 2h). Aquellos que, como lo afirmó el anarquista Piotr Kropotkin (1996), en su mejor expresión estarían basados en dinámicas de auto-organización. Kropotkin lo denomina como ayuda-mutua. Pero este ya es el tema de otro trabajo.

\section{Referencias}

AquariumPros.inc (2010). Fish School. Recuperado de http://aquariumprosmn.com/2010/01/460/

Arrow, K. (1950). A Difficulty in the Concept of Social Welfare. The Journal of Political Economy, 58(4), 328-346. 
Avicultura.com (2012). Petersime publica un folleto sobre la incubación basada en la respuesta del embrión. Recuperado de http://www.avicultura. com/2012/03/02/petersime-publica-un-folleto-sobre-la-incubacionbasada-en-la-respuesta-del-embrion/

Bak, P., Tang, C., \& Wiesenfeld, K. (1988). Self-organized criticallity. Physical Review, 38(1), 364-374.

Barrat, A., Barthélemy, M., \& Vespignani, A. (2009). Dynamical Processes on Complex Networks. Cambridge: Cambridge University Press.

Bodin, ö., \& Norberg, J., (2005). Information Network Topologies for Enhanced Local Adaptive Management. Environmental Management, 35(2), 175-193.

Bogason, P., \& Musso, J. A., (2006). The Democratic Prospects of Network Governance. The American Review of Public Administration, 36(3), 3-18. Bonabeau, E., Dorigo, M., \& Theraulaz, G. (1999). Swarm Intelligence. From Naural to Artificial Systems. New York: Oxford University Press.

Cacino, C., (2008). La Muerte de la Ciencia Política. Buenos Aires: Sudamericana. Camazine, S., Deneubourg, J. L., Franks, N. R., Sneyd, J., Theraulaz, G., Bonabeau, E. (2001). Self-Organization in Biological Systems. Princeton, New Jersey: Princeton University Press.

Colomer, J. M. (2001). Desequilibrium Institutions and Pluralist Democracy. Journal of Theoretical Politics, 235-247.

Crumley, C. L., (1995). Heterarchy and the Analysis of Complex Societies. Archeological Papers of the American Anthropological Association. Special Issue: Heterarchy and the Analysis of Complex Societies, 6(1), 1-5.

Easton, D. (1981). The Political System: An Inquiry into the State of Political Science. Chicago: University of Chicago Press.

Easton, D., (2006). Esquema para el Anlisis Político. Buenos Aires: Amorrortu. Elgie, R., (1998). The Classification of Democratic Regime Types: Conceptual Ambiguity and Cotestable Assumptions. European Journal of Political Research, 219-238.

Estrada, E. (2012). The Structure of Complex Networks. Oxford: Oxford University Press.

Fairtlough, G. (2006). The Three Wyas of Getting Things Done. Axminster: Truarchy Press.

Finearteamerica.com (2013). A Herd of Zebras and a Sole Wildbeestanada de Zebras, fotografía digital. Recuperado de http://fineartamerica.com/ featured/a-herd-of-zebras-and-a-sole-wildebeest-bobby-haas.html 
Fraley, D. J. (2010). Ubiquity Symposium “What is Computation?”: Computation is Process Ubiquity, Issue November, 1-6.

Hobbes, T. (1928). Leviathan, or the Matter, Form and Power of a Commonwealth Ecclesiasticall and Civil. Yale: Yale University Press.

Holland, J., (1995). Hidden Order, How Adaptation Builds Complexity. New York: Basic Books.

Holland, J. (2000). Emergence, From Chaos to Order. New York: Oxford University Press.

Huffingtonpost.com (2011). Protests in Yemen. Recuperado de http:/ /www. huffingtonpost.com/2011/04/19/yemen-protesters-killed_n_851149. html

Ilanes, J., Orellana, C., Fertilio, B., Leyton, V., \& Venegas, F. (2007). Análisis Macroscópico y Microscópico del Desarrollo Fetal en el Gato (Felis Catus), en Relación con el Desarrollo del Tamaño de la Vesícula Coriónica y de la Placenta. International Journal of Morphology, 25(3), 467-481.

Kauffman, S. (1995). At Home in the Universe: The Search for the Laws of SelfOrganization and Complexity. New York: Oxford University Press.

Kropotkin, P. (1996). Mutual Aid: A Factor of Evolution. Montreal: Black Rose Books.

Lapierre, J.-W. (1976). El Análisis de los Sistemas Politicos. Barcelona: Península. Locke, J. (1988). Two Treatises of Government. Cambridge: Cambridge University Press.

Lorenz, E. (1963). Deterministic Non-Periodic Flow. Journal of the Atmospheric Sciences, 20(2), 130-141.

Lyon, B. (2003). Visual Complexity, Manuel Lima. Recuperado de http:// www.visualcomplexity.com $/$ vc/project_details.cfm?id=70\&index $=$ 10\&domain $=$ Internet

Machiavelli, N. (1910). The Prince. New York: PF Collier.

Mainzer, K. (2007). Thinking in Complexity. The Computational Dynamics of Matter, Mind an Minkind. Berlin: Springer.

Maldonado, C. E. (2014). ¿En qué sentido puede decirse que las relaciones internacionales son un fenómeno complejo adaptativo?, ponencia presentada en el III Congreso Colombiano de Relaciones Internacionales, Medellín.

Maldonado, C. E., \& Gómez Cruz, N. A., (2011). El Mundo de las Ciencias de la Complejidad. Bogotá: Universidad del Rosario. 
Meek, J. W., Ladurantey, J. D., \& Newell, W. H. (2007). Complex Systems, Governance and Policy. Emergence: Complexity and Organizations, 1(2), 24-36.

Mezza-Garcia, N. (2013). Bio-Inspired Political Systems: Opening a Field. Switzerland, Springer, 758-812.

Nasa.gov (2007). Galaxy M81. Recuperado de http://www.nasa.gov/mission_pages/spitzer/multimedia/spitzer-20070604.html

Nicolis, G., \& Prigogine, I. (1977). Self-Organization in Non-Equilibrium Systems. New York: Wiley \& Sons.

O' Toole, L. (2004). Shaping Formal Networks Through the Regulatory Processes. Administration and Society, 36(2), 186-207.

Prettejohn, B., Berryman, M. J., \& McDonnell, M. D. (2011). Methods for Generating Complex Networks with Selected Structural Properties for Simulations: a review and tutorial for neuroscientists. Frontiers in Computational Neuroscience, 5(11), 1-18.

Princeton.edu (2013). Flock of Starlings. Recuperado de http://www. princeton.edu/main/news/archive/S36/02/56I00/index. $\mathrm{xml}$ ?section $=$ topstories

Rossi, M. A., \& Rodríguez, L. (2007). Complejidad y Emergencia de la Organización Política de la Polis Griega en el Pensamiento de Aristóteles como Sistema Complejo. Cinta de Moebio, 30, 245-261.

Rousseau, J. (2002). The Social Contract: And the First and Second Discourses. Yale: Yale University Press.

Sawyer, R. K. (2005). Social Emergence: Societies as Complex Systems. Cambridge, New Jersey: Cambridge University Press.

Solé, R. (2011). Phase Transitions. New Jersey: Princeton University Press. Tiezzi, E. (2006). La Belleza y la Ciencia. Hacia una Visión Integradora de la Naturaleza. Barcelona: Icaria.

Vernant, J.-P. (1992). Los orígenes del pensamiento griego. Barcelona: Paidós

Vogel, S. (2000). Ancas y Palancas, Mecánica Natural y Mecánica Humana. Barcelona: Metatema, Tusquets.

Wachhaus, A., (2012). Anarchy as a Model for Network Governance. Public Administration Review, 72(1), 33-42.

Waddington, C. (2012). The Epigenotype. International Journal of Epidemio$\log y, 41(1), 10-13$.

Watts, D. (2003). Six Degrees. The Science of a Connected Age. New York: Norton \& Company. 
158 I Nathalie Mezza-Garcia, Carlos Eduardo Maldonado

Weaver, W. (1948). Science and Complexity. American Scientist, 36, 536.

Wilson, E. O., \& Hölldobler, B. (1998). Dense Heterarchies and Mass Communication as the Basis of Organization in Ant Colonies. Ecology and Evolutions, 3, 65-68. 